\title{
EDI SUROJO MEDIA PENGENALAN KEBUDAYAAN LOKAL BERBASIS KARAKTER UNTUK ANAK USIA DINI
}

\author{
Fatimah Noor Isnaini, Dwi Lestari, Metri Utami Krahayon, Hana Ika Safitri \\ Pendidikan Guru Pendidikan Anak Usia Dini, Fakultas Ilmu Pendidikan, \\ Universitas Negeri Yogyakarta \\ e-mail: fatimah.noor@student.uny.ac.id, dwi705@student.uny.ac.id, \\ metri.utami@student.uny.ac.id, hana840fip@student.uny.ac.id
}

\begin{abstract}
Abstrak
Berdasarkan hasil wawancara dengan beberapa guru dapat disimpulkan bahwa pengenalan tokoh wayang dan cerita wayang sangat penting dikenalkan sejak dini karena dalam cerita wayang mengandung petunjuk atau teladan yang dapat diteladani oleh anak usia dini. Namun sekarang ini wayang tidak banyak dikenal karena penelitian menunjukkan bahwa para guru dan kepala TK belum memiliki kemampuan dalam mengembangkan materi dan media pembelajaran wayang serta kurangnya pemahaman guru TK tentang wayang. Oleh karena itu, perlu dirancang media untuk mengenalkan tentang tokoh wayang pada anak usia dini. Penulis membuat sebuah media berbentuk Edi Surojo (Ensiklopedia Superhero Jowo) Tiga Dimensi sebagai Media Pengenalan Kebudayaan Lokal Berbasis Karakter Untuk Anak Usia Dini. Metode yang diterapkan dalam melaksanakan program ini merupakan sebuah rangkaian tahapan yang disusun secara sistematis, berikut adalah tahapan-tahapan yang dilakukan : Persiapan umum, pembuatan isi, dan pembuatan desain. Media seperti Ensiklopedia Superhero Jowo diharapkan dapat menjadi alternatif untuk mengenalkan kebudayaan lokal pada anak usia dini serta mengembangkan nilai-nilai pendidikan karakter melalui tokoh wayang. Potensi berkelanjutan Ensiklopedia Superhero Jowo adalah menjadi media dalam mengenalkan budaya-budaya lokal yang ada di Indonesia yaitu tokoh pewayangan. Dengan adanya Ensiklopedia Superhero Jowo dapat mempermudah guru dalam mengenalkan budaya lokal berbasis karakter pada anak usia dini.
\end{abstract}

Kata Kunci: Pendidikan karakter, wayang, superhero jowo, anak usia dini

\begin{abstract}
Based on interviews with some teachers that introducing puppet and puppet story is very important for early childhood because it introduced wayang stories that give good values that can be imulated by young children. But now, the puppet is not widely known. Research shows that teachers and principals from kindergarten yet have the ability to develop materials and instructional media about puppets kindergarten teachers and a lack of understanding about the puppet. Therefore, the media should be designed to introduce about puppet in early childhood. The author makes an Edi Surojo (Ensiklopedia Superhero Jowo) Three Dimensions as Media Recognition Based Local Culture Character For Early Childhood. The research methods that used for this program is a series of stages that are arranged systematically, the following steps are performed: Preparation general, content creation, design and manufacture. Media such as the Ensiklopedia Superhero Jowo is expected to be an alternative to introducing the local culture in early childhood and develop the values of character education through puppet. Continuous Potential of Ensiklopedia Superhero Jowo are becoming media for
\end{abstract}


introducing the local culture in Indonesia. Ensiklopedia Superhero Jowo can facilitate teachers to introducing the local culture-based character in early childhood.

Keywords: character education, puppet, javanesse superhero, early childhood

\section{PENDAHULUAN}

Bangsa Indonesia merupakan bangsa yang kaya akan seni dan budaya. Salah satu budaya bangsa Indonesia adalah wayang. Wayang merupakan seni pertunjukan asli dari Indonesia yang selalu menceritakan nilai-nilai, norma, tradisi dan budaya yang tumbuh dan berkembang dalam kehidupan masyarakat lokal yang bermanfaat untuk membangun karakter dan jati diri bangsa Indonesia yang tergambarkan melalui watak tokoh dalam wayang (Nur Fajrie, 2013). Pembangunan karakter dan pendidikan karakter menjadi suatu keharusan karena pendidikan tidak hanya menjadikan peserta didik menjadi cerdas, tetapi juga harus mempunyai budi pekerti dan sopan santun sehingga keberadaannya sebagai anggota masyarakat menjadi bermakna baik bagi dirinya maupun masyarakat (Ejournal UNP :2012). Pendidikan karakter harus diterapkan sejak dini baik di lingkungan kelurga, masyarakat maupun di lingkungan sekolah. Sejauh ini perhatian pemerintah dan masyarakat terhadap arti penting pendidikan anak usia dini menunjukkan kecenderungan yang semakin meningkat. Ditetapkannya pasal tentang pendidikan anak usia dini dalam Undang Undang Sisdiknas Nomor 20 tahun 2003 dan berbagai kebijakan pengembangan sebagai implementasinya merupakan satu bukti dari perhatian tersebut.

Namun sekarang ini wayang tidak banyak dikenal. Jangankan mengenal ceritanya, banyak yang tidak mengetahui tokoh-tokoh pewayangan (Nur Fajrie, 2013). Pendapat tersebut diperkuat dengan penelitian yang telah dilakukan oleh peneliti. Berdasarkan penelitian yang telah peneliti lakukan di empat TK dapat diambil kesimpulan bahwa sebagian besar anak usia dini tidak mengenal tokoh pewayangan yang ada di Indonesia. Peneliti mencoba memberikan gambar wayang pada anak usia dini tetapi anak tidak mengetahui dan tidak mengenal tokoh pewayangan yang peneliti bawa padahal tokoh tersebut merupakan tokoh yang familiar. Cerita pewayangan juga dapat dijadikan media untuk mendidik karakter anak karena cerita pewayangan mengandung falsafah hidup yang dapat dijadikan tuntutan hidup sehari-hari. Berdasarkan hasil wawancara dengan beberapa guru dapat disimpulkan bahwa pengenalan tokoh wayang dan cerita wayang sangat penting dikenalkan sejak dini karena dalam cerita wayang mengandung petunjuk atau teladan yang dapat diteladani oleh anak usia dini.

Saat ini anak-anak bangsa Indonesia sangat menggandrungi budaya asing seperti tokoh pahlawan super luar negeri melalui komik, film, animasi, maupun game (Tandrie Putra Rahmanda). Pendapat tersebut sesuai dengan penelitian yang telah peneliti lakukan. Berdasarkan penelitian yang telah peneliti lakukan di empat TK di provinsi Daerah Istimewa Yogyakarta, dapat disimpulkan bahwa sebagian besar anak-anak menyukai tokoh superhero luar negeri. Ketika peneliti memperlihatkan gambar tokoh superhero luar negeri seperti batman, superman, spiderman anak-anak langsung mengetahui nama dan kekuatannya. Ketika ditanya, anak-anak mengaku mengetahui tokoh superhero tersebut dari televisi dan youtube. 
Anak-anak suka meniru apa yang dilihat termasuk meniru adegan, pesan, dan nilai yang dibawakan oleh pahlawan super tersebut. Pahlawan super yang digemari anak dari luar negeri tentunya banyak mengandung unsur budaya luar, padahal Indonesia memiliki tokoh pahlawan super yang ada pada lakon pewayangan. Namun keberadaannya kalah dengan superhero dari luar negeri karena kurangnya media dan sosialisasi untuk mengenalkan tokoh wayang tersebut.

Memperkenalkan sesuatu kepada anak hendaknya dimulai dari benda-benda konkret. Media diperlukan dalam pengenalan sebuah konsep untuk anak. Media berperan atau memiliki kedudukan sebagai sarana bagi seseorang untuk mengekspresikan diri (Djamarah, 2006:120). Pemanfaatan media pembelajaran dapat membangkitkan keinginan dan minat baru, meningkatkan motivasi dan rangsangan kegiatan belajar, dan bahkan berpengaruh secara psikologis kepada siswa (Hamalik, 1986). Namun berdasarkan penelitian menunjukkan bahwa para guru dan kepala TK belum memiliki kemampuan dalam mengembangkan materi dan media pembelajaran wayang serta kurangnya pemahaman guru TK tentang wayang. Para guru dan kepala TK sepakat untuk membelajarkan wayang di TK, asalkan dalam berbagai hal mereka perlu diberi bekal. Bekal yang dimaksud terkait dengan pengembangan materi dan media pembelajarannya berdasar kurikulum yang ada. Selain itu berdasarkan wawancara dengan beberapa guru, guru mengharapkan pemerintah juga ikut berperan dalam mengenalkan wayang untuk anak usia dini. Harapan guru pemerintah segera memberikan pelatihan atau diklat untuk guru tentang materi pewayangan, agar guru nantinya mampu mengajarkan pada anak usia dini.

Berdasarkan latar belakang di atas, perlu dirancang media untuk mengenalkan tentang superhero jowo pada anak usia dini. Oleh karena itu penulis membuat sebuah media berbentuk Edi Surojo (Ensiklopedia Superhero Jowo) Tiga Dimensi Sebagai Media Pengenalan Kebudayaan Lokal Berbasis Karakter Untuk Anak Usia Dini.

\section{METODE}

Jenis penelitian yang digunakan oleh peneliti adalah pendekatan rancang bangun atau research and development. Metode penelitian ini merujuk pada model Borg \& Gall dengan sedikit penyesuaian sesuai kontek penelitian. Rancangan pengembangan model research and development yang diadopsi oleh peneliti dalam pengembangkan produknya terdapat 6 langkah diantaranya yaitu:analisis kebutuhan,perencanaan isi, desain produk, validasi desain, revisi desain, uji coba produk.

\section{Gambar 1. Tahap Pengembangan Produk}
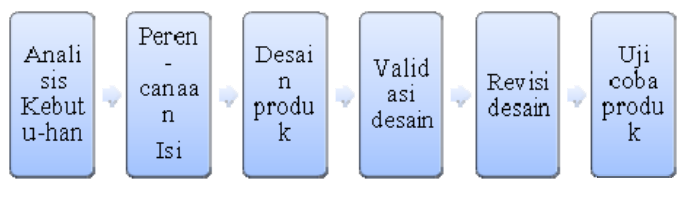

\section{Tahap analisis kebutuhan}

Tahap analisis kebutuhan merupakan tahapan untuk mengidentifikasi danmendapatkan data mengenai apa saja yang diperlukan dalam perancanaan dan pengimplementasiaan sistem serta pemikiran untuk perancangan selanjutnya. Tahap ini dilakukan 
identifikasi data yang diperlukan untuk mengembangkan EDISUROJO (Ensiklopedia Super Hero Jowo) tiga dimensi sebagai media pengenalankebudayaan lokal berbasis karakter untuk anak usia dini. Langkah yang dilakukan pada tahap analisis meliputi.Pada tahap ini kami melakukan persiapan secara matang sebelum pelaksanaan program. Pada tahap ini kami melakukan 5 kegiatan:

a) Pembagian tugas untuk melaksanakan penelitian sosial humaniora. Pembagian tugas tersebut dilakukan melalui diskusi dan musyawarah bersama. Pembagian tugas disesuaikan dengan bidang dan keahlian masing-masing.

b) Pemilihan TK untuk sampel penelitian di 5 daerah di provinsi D.I. Yogyakarta yaitu Kabupaten Bantul, Sleman, Gunungkidul, Kulonprogo, dan kota Yogyakarta.

c) Meminta ijin kepada TK yang bersangkutan dan membuat surat ijin observasi.

d) Melakukan observasi terkait pengetahuan anak dan guru tentang tokoh-tokoh super hero jowo serta mensosialisasikan Ensiklopedia Superhero Jowo pada guru. Tujuan dari observasi ini adalah untuk mengetahui seberapa jauh guru dan anak mengenal tentang budaya lokal terutama wayang serta mencari tahu seberapa penting pengenalan wayang pada anak usia dini, media yang cocok untuk mengenalkan tokoh pewayangan pada anak usia dini. Observasi guru dilakukan dengan pengisian angket dan wawancara seputar pengenalan budaya lokal khususnya wayang pada anak usia dini.

e) Indentifikasi awal. Tahap ini terdiri dari (1) observasi pengetahuan anak tentang tokoh-tokoh wayang. (2) wawancara terhadap guru dan kepala sekolah tentang media pengenalan wayang pada saat ini dan media yang cocok untuk mengenalkan wayang pada anak usia dini. (3) dokumentasi.

\section{Perencanaan Isi}

Tahap perencanaan isi Ensiklopedia Superhero Jowo merupakan hal yang penting sebelum melakukan tahapan berikutnya. Perencanaan isi dimulai dari pemilihan tokoh wayang yang akan dimasukkan kedalam buku tersebut. Tokoh pewayangan yang dipilih ialah Gatotkaca, Anoman, Bima, Arjuna, Kumbakarna, dan Antareja.Pemilihan tokoh wayang didasari oleh sifat-sifat, karakter, serta kekuatan super yang dimiliki oleh tokoh pewayangan tersebut. Setelah memilih tokoh wayang yang akan dimasukkan maka tahapan selanjutnya adalah menentukan cerita pewayangan yang akan dimasukkan dalam Ensiklopedia Superhero Jowo. Pemilihan cerita wayang disesuaikan dengan karakter anak usia dini. Cerita pewayangan diambil pada bagian yang menarik bagi anak dan mudah dipahami oleh anak sehingga karakter yang akan disampaikan bisa langsung diterima oleh anak.

\section{Desain Produk}

Setelah menentukan isi, tahapan selanjutnya adalah pembuatan desain produk.Desain produk merupakan sebuah gambaran untuk menjelaskan gambaranmodel EDI SUROJO (Ensiklopedia Super Hero Jowo) tiga dimensi terkait dengan tampilan, ukuran, dan warna. Desain dibuat dengan tampilan yang menarik, mudah digunakan, dan mudah dipahami.

Pembuatan desain disesuaikan dengan karakter anak tanpa meninggalkan unsur-unsur wajib yang ada pada tokoh pewayangan.Pembuatan desain dimulai dari membuat desain latar, pemilihan ikon Indonesia, serta pemilihan warna. 


\section{Validasi desain}

Validasi desain EDI SUROJO (Ensiklopedia Super Hero Jowo) adalah proses mengetahui kekurangan dan kesalahan dari desain yang dibuat untuk menentukan kelayakan penggunaanEDI SUROJO (Ensiklopedia Super Hero Jowo) sebagai media untukmengenalkan kebudayaan lokal berbasis karakter. Pada tahap ini meliputi proses pengujian oleh ahli mencakup ahli media dan ahli budaya. Ahli media ialah Novan Edo dan ahli budaya yaitu Gondhol Sumargiono.

\section{Revisi Desain}

Revisi desain mencakup perbaikan EDI SUROJO (Ensiklopedia Super Hero Jowoagar layak digunakan sebagai media pengenalan kebudayaan lokal berbasis karakter untuk anak usia dini. Revisi desain terdiri dari revisi unsurunsur yang terdapat dalam wayang, background, bentuk dan ukuran wayang serta deskripsi singkat mengenai tokoh pewayangan.

\section{Uji Coba Produk}

Tahap pengujian produk dilakukan kepada subyek yang akan diteliti. Subyek penelitian disini adalah peserta didik dengan rentang usia 5-6 tahun. Implementasi dilakukan dengan media EDI SUROJO (Ensiklopedia SuperHero Jowo) yang telah di buat secara sederhana, mudah di pahami, dan menarikpeserta didik.

\section{HASIL DAN PEMBAHASAN}

\begin{tabular}{lrr}
\multicolumn{3}{c}{ Pengenalan budaya lokal } \\
berbasis karakter melalui media \\
Ensiklopedia Superhero Jowo memiliki \\
beberapa keunggulan. Disamping \\
bentuk yang menarik, latar desain \\
Ensiklopedia Superhero & Jowo \\
mengangkat kebudayaan lokal \\
Indonesia berupa wayang dan \\
kebudayaan lokal lainnya yaitu rumah
\end{tabular}

adat, tempat wisata dan tempat bersejarah di Indonesia.

Dalam proses pelaksanaan pengembangan media Ensiklopedia Superhero Jowo peneliti melakukan penelitian tentang pengetahuan anak dan guru akan tokoh pewayangan. Penelitian tersebut dilakukan TK di 4 wilayah D.I. Yogyakarta yaitu Kabupaten Bantul, Sleman, Kulonprogo, dan kota Yogyakarta. Pada penelitian awal ini dilakukan bertujuan untuk mengetahui pengetahuan guru dan siswa tentang tokoh-tokoh pewayangan terutama tokoh superhero jowo. Teknik penelitian yang digunakan yaitu observasi dan wawancara. Observasi ini mengambil sasaran anakanak TK dan guru-guru di ke empat wilayah yang telah dipilih. Penelitian awal ini dilakukan dengan beberapa tahapan. Tahap yang pertama yaitu superhero seperti batman, superman, dan spiderman pada anak, peneliti melihat bagaimana respon anak terhadap gambar-gambar tersebut. Tahap selanjutnya anak diperlihatkan pada gambar-gambar superhero jowo seperti Gatotkaca, Kumbakarna, Arjuna,Bima, Anoman, dan Antareja kemudian peneliti melihat respon anak terhadap gambar tersebut. Tahap selanjutnya anak diberi tahu tentang nama-nama gambar superhero jowo tersebut. Setelah itu peneliti melakukan wawancara kepada guru untuk mengetahui seberapa jauh pengetahuan guru tentang budaya lokal terutama tentang tokoh wayang. Dalam penelitan tersebut peniliti memperoleh kesimpulan bahwa pengetahuan wayang guru TK di empat wilayah tersebut sangat minim. Guru hanya sebatas tahu nama-nama wayang, guru tidak tahu tentang ciri-ciri wayang serta karakter yang dimilikinya.

Setelah melakukan penelitian awal tahap selanjutnya yaitu pembuatan 
isi Ensiklopedia Superhero Jowo. Pembuatan isi dilakukan dengan pengkajian bebebapa sumber pustaka tentang tokoh-tokoh wayang. Dari sekian banyak tokoh pewayangan dipilah berdasarkan karakteristik superhero. Karakteristik superhero yang dimaksud ialah mempunyai jiwa kepemimpinan, kepahlawanan, cinta tanah air, kesetiaan, membela kebenaran, kejujuran, kegigihan serta tanggungjawab. Dari hasil seleksi kemudian terpilih enam tokoh wayang yaitu Anoman, Kumbakarna, Gatotkaca, Arjuna Bima, dan Antareja. Keenam tokoh tersebut menjadi isi dalam Ensiklopedia Superhero Jowo. Desain dibuat dengan menarik sesuai karakteristik anak dengan tidak meninggalkan unsur-unsur asli pada wayang. Berikut adalah deskripsi singkat keenam tokoh pewayangan yang dimasukkan dalam Ensiklopedia Superhero Jowo.

Anoman merupakan tokoh pewayangan berwujud kera putih. Anoman berasal dari Kesatriyan Kendhalisada. Anoman memiliki banyak kekuatan di antaranya aji sepiangin yaitu berjalan tanpa jejak dan aji mundri yaitu dapat menambah berat tubuhnya sehingga musuh tidak bisa mengangkatnya. Kekuatan lain yang dimiliki Anoman adalah aji pameling, bayu bajra, bayu ronta, aji pancasona, dan kuku pancanaka. Salah satu kemampuan Anoman ialah kemampuan untuk hidup abadi. Anoman memiliki watak santosa ing tekad, kendel, jujur, bekti lan setya dhateng Gusti.

Kumbakarna merupakan tokoh pewayangan yang berwujud raksasa yang berasal dari Negara Alengka. Meskipun berwujud raksasa, Kumbakarna memiliki watak gadhah jiwa satriya, jujur, bela tumindak leres, dan tansah ngrungkepi pertiwi. Kumbakarna memiliki kekuatan gedhong menga yang menyebabkan Kumbakarna dapat makan dalam jumlah banyak dan pethakgelak sakethi yaitu sanggup membentak dengan keras sehingga lawannya dapat terpental jauh.

Gatotkaca merupakan ksatria perkasa berotot kawat dan bertulang besi. Gatotkaca mempunyai senjata kotang antrakusuma sehingga dapat terbang di angkasa dan duduk di atas awan. Senjata lain yang dimiliki Gatotkaca di antaranya caping basunandha atau penutup kepala gaib yang mengakibatkan ia tidak akan kehujanan dan kepanasan serta terompah padakacarna sehingga tendangan Gatotkaca sangat kuat. Gatotkaca mempunyai sifat tanggih wutuh sepuh, manjing ajur ajer, pinter, lan tanggung jawab.

Arjuna merupakan ksatria yang mahir memanah. Arjuna memiliki sifat tansah aih, remen tetulung, sekti tanpa aji-aji, nglurug tanpa bala, lan satriya socaning bathara. Kekuatan yang dimiliki Arjuna antara lain panglimuyan yang dapat membuat dirinya tidak terlihat, sepiangin atau dapat berjalan tanpa jejak, tunggengmaya yaitu dapat menciptakan sumber mata air, dan lahima yaitu dapat membuat tubuhnya menjadi ringan sehingga dapat melayang. Arjuna juga mempunyai berbagai senjata pemberian para dewa yaitu panah pasopati dan keris pulanggeni.

Bima merupakan tokoh pewayangan penjelmaan dari Dewa Bayu atau Dewa Angin. Bima memiliki tubuh yang sangat kuat, berperawakan tinggi besar, dan gagah perkasa. Bima memiliki kuku panjang dan kuat yang menjadi senjata alami yang disebut $k u k u$ pancanaka. Bima mempunyai senjata gada yang disebut gada rujakpolo. Bima memiliki sifat lugu, jujur, prasaja, tan mendha saking bebaya, tan 
wedi guntur teka kang sinedya, lan kang cinipta dadi.

Antareja merupakan tokoh pewayangan yang dapat hidup di dalam air. Kulitnya terlindung oleh sisik yang membuatnya kebal terhadap senjata. Antareja mempunyai sifat tatag, tangguh tanggon, tandang mara tangan, lan sluman slumun slamet. Antareja memiliki kekuatan ajian upasanta. Air liurnya bisa membinasakan lawannya dalam waktu sekejap. Kulitnya bersisik napakawaca yang mampu menahan serangan senjata. Antareja juga memiliki cincin mustikabumi yang bisa digunakan untuk menghidupkan orang yang mati di luar takdir.

\section{Media seperti Ensiklopedia} Superhero Jowo diharapkan dapat menjadi alternatif untuk mengenalkan kebudayaan lokal pada anak usia dini serta mengembangkan nilai-nilai pendidikan karakter melalui tokoh wayang. Karakteristik anak usia dini memerlukan pembelajaran yang kongkrit, terus-menerus, dan menyenangkan. Media Ensiklopedia Superhero Jowo menjadi pilihan untuk melaksanakan pengembangan pendidikan karakter anak.

Potensi berkelanjutan

Ensiklopedia Superhero Jowo adalah menjadi media dalam mengenalkan budaya-budaya lokal yang ada di Indonesia yaitu tokoh pewayangan. Dengan adanya Ensiklopedia Superhero Jowo dapat mempermudah guru dalam mengenalkan budaya lokal berbasis karakter pada anak usia dini. Guru dapat mengenalkan budaya lokal pada anak dengan media yang praktis dan menarik. Berdasarkan hasil wawancara yang dilakukan oleh peneliti guru sangat mendukung adanya media pengenalan wayang pada anak usia dini karena pengenalan wayang mengandung unsurunsur kebudayaan serta karakter wayang dapat dijadikan teladan bagi anak.

\section{KESIMPULAN}

Berdasarkan hasil penelitian dan wawacara di 4 wilayah Daerah Istimewa Yogyakarta dapat ditarik kesimpulan bahwa para pendidik membutuhkan media untuk mengenalkan budaya lokal berbasis karakter pada anak usia dini khususnya budaya tentang wayang. Oleh karena itu peneliti membuat Edi Surojo (Ensiklopedia Superhero Jowo) Tiga Dimensi Sebagai Media Pengenalan Kebudayaan Lokal Berbasis Karakter Untuk Anak Usia Dini.

\section{UCAPAN TERIMAKASIH}

Terimakasih kepada bapak Joko Pamungkas, M.Pd. yang telah memberikan bimbingan kepada tim PKM Edi Surojo (Ensiklopedia Superhero Jowo).

\section{DAFTAR PUSTAKA}

Djamarah Syaiful Bachri. 2006. Strategi Belajar Mengajar. Bandung: Sinar Baru.

Hamalik, O. 1994. Media Pendidikan, cetakan ke-7. Bandung: Penerbit PT. Citra Aditya Bakti.

Nur Fajrie. 2013. Media Pertunjukan Wayang Untuk Menumbuhkan Karakter Anak Bangsa. Jurnal PGSD-FKIPUniversitas Muria Kudus.

Sujamto. 1992. Re- Oreintasi dan Revitalisasi: Pandangan Hidup Masyarakat Jawa Semarang: Dahara Prize.

Syarif, M. Ibnan. 2007. "Pengembangan Model Pembelajaran Wayang Di TK sebagai Upaya Pengenalan, Pelestarian, Dan Penanaman Nilai Sejak Dini”, 
Laporan Penelitian, Universitas Negeri Semarang.

Syafii, M.Ibnan Syarif, Syakir. Pengembangan Kurikulum Dan Media Pembelajaran Wayang Di Taman Kanak-Kanak Di Kota Semarang

Tandrie, Putra, Rahmanda ${ }_{\text {Kerancangan }}$. Pahlawan Super Beridentitas Budaya Lokal Untuk Menanamkan Nilai - Nilai Cinta Lingkungan Designing Superheroes Comics With Local Culture Identity For Embedding Save The Nature Value. Jurnal eproc.pdf.

Vivit Risnawati.2012. Optimalisasi Pendidikan Karakter Anak Usia Dini Melalui Sentra Main Peran di Taman KanakKanak Padang. Jurnal Pesona PAUD Vol.1.No.1 